\title{
Correction to: Nanoceramics and novel functionalized silicate-based magnetic nanocomposites as substitutional disinfectants for water and wastewater purification
}

\author{
Ali B. Abou Hammad ${ }^{1}$ - Amany M. El Nahrawy ${ }^{1}$ - Bahaa A. Hemdan ${ }^{2}$ - Akebe Luther King Abia ${ }^{3}$ (D) \\ Published online: 10 June 2020 \\ (C) Springer-Verlag GmbH Germany, part of Springer Nature 2020
}

Correction to: Environmental Science and Pollution Research https://doi.org/10.1007/s11356-020-09073-9

The correct name of the 2nd Author is presented in this paper.

Publisher's note Springer Nature remains neutral with regard to jurisdictional claims in published maps and institutional affiliations.

The online version of the original article can be found at https://doi.org/ 10.1007/s11356-020-09073-9

\footnotetext{
Bahaa A. Hemdan

bahaa_nrc@yahoo.com

$\triangle$ Akebe Luther King Abia

lutherkinga@yahoo.fr

1 Solid-State Physics Department, Physics Research Division, National Research Centre, 33 El-Bohouth St., Dokki, Giza 12622, Egypt

2 Water Pollution Research Department, Environmental Research Division, National Research Centre, 33 El-Bohouth St., Dokki, Giza 12622, Egypt

3 Antimicrobial Research Unit, College of Health Sciences, University of KwaZulu-Natal, Durban X54001, South Africa
} 